\title{
Modification of surface antigens in blood CD8+ T-lymphocytes in COPD: effects of smoking
}

\author{
A. Koch*, M. Gaczkowski*, G. Sturton\#, P. Staib", T. Schinköthe ", E. Klein*, \\ A. Rubbert ${ }^{\star}$, K. Bacon ${ }^{+}$, K. Waßermann* and E. Erdmann*
}

ABSTRACT: In contrast to the effects of cigarette smoke on T-lymphocyte subsets in the airways, it has not yet been determined whether smoking has immunomodulatory effects on surface antigens of peripheral blood T-lymphocytes and, if that is the case, whether these effects differ in smokers with and without chronic obstructive pulmonary disease (COPD).

The present authors have, therefore, examined the expression of the surface activation marker CD28, the levels of cytotoxic effector lymphocytes (CD27-/CD45RA+) and the expression of the lung type (Tc)1-specific chemokine receptor $\mathrm{CXCR}_{3}+$ on peripheral blood CD8+ T-lymphocytes. The present authors have also studied the chemotactic activity of CD8+ T-lymphocytes on monocyte chemotactic protein (MCP)-1 and compared 13 nonsmoking controls, 12 smokers with COPD and 14 smokers without airflow limitation.

There was a decrease in the total count of CD8+ T-cells and an increase in the CD4+/CD8+ ratio in smokers with COPD compared with smokers without COPD and controls. Expression of the Tc1-specific chemokine receptor $\mathrm{CXCR}_{3}+$ by CD8+ T-cells was increased in smokers with COPD compared with smokers without COPD and controls.

The expression of activated and of cytotoxic effector CD8+ T-cells in smokers with and without COPD showed an increase compared with controls. CD8+ T-cells from smokers with and without COPD showed a decrease in chemotactic activity to MCP-1 compared with controls.

In conclusion, chronic obstructive pulmonary disease may be a systemic immunomodulatory disease associated with the modification of surface antigens in blood CD8+ T-lymphocytes.

KEYWORDS: Chemokine receptor $\mathrm{CXCR}_{3}$, chronic obstructive pulmonary disease, cigarette smoking, cytotoxic effector T-cells, peripheral blood CD8+ T-lymphocytes

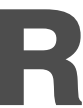
ecent evidence suggests that lung type 1 (Tc1) CD8+ T-lymphocytes are implicated in the pathogenesis of chronic obstructive pulmonary disease (COPD) [1]. However, there is little information regarding the role of peripheral blood CD8+ T-cells and the importance of their activation and cytotoxic/effector phenotype in this context.

Cigarette smoke is the main risk factor for developing COPD and exerts its primary effects on the lungs. However, there is clear evidence indicating the systemic effects of cigarette smoke, including an increase in the incidence of coronary disease, cancers of various organs and acute and chronic respiratory tract infections [2, 3]. Such effects may reflect cigarette smoke-induced impairment of the immune system [4] associated with T-cell anergy and modulatory effects on antigen-mediated signalling in T-lymphocytes
[5]. However, phenotype differences in circulating lymphocyte populations in smokers with and without COPD have not been directly compared.

Studies suggest that the proportion of peripheral blood CD8+ T-lymphocytes in smokers with COPD correlates significantly with the diffusing capacity of the lung for carbon monoxide (DL,CO). This results in a smaller proportion of CD8+ Tlymphocytes and a higher CD4+/CD8+ ratio in a COPD cohort with low DL,CO per unit of alveolar volume $(D \mathrm{~L}, \mathrm{CO} / V \mathrm{~A})$ than in a COPD cohort with normal $D \mathrm{~L}, \mathrm{CO} / V \mathrm{~A}$ [6]. This suggests that peripheral blood T-lymphocyte abnormalities might be involved in the pathogenesis of airflow limitation. GLADER et al. [7] reported that cigarette smoking may induce a higher number of peripheral blood CD4+ T-cells than in subjects who have never smoked and smokers with COPD. Moreover, MAJORI et al. [8] examined Tc1/Tc2-cell

\section{AFFILIATIONS}

*Dept of Pneumology, Clinic III for Internal Medicine, and "Dept of Haematology, Clinic I for Internal Medicine, University of Cologne, Cologne, Germany. \#Thoracic Medicine, Imperial College at National Heart \& Lung Institute, London, and +Bayer Ltd, Stoke Court, Berkshire, UK.

CORRESPONDENCE

A. Koch

University of Cologne Dept of Pneumology Medical Clinic III

Joseph-Stelzmann-Str. 9 50924 Köln

Cologne

Germany

Fax: 492214783137

E-mail: andrea.koch@uni-koeln.de

Received:

November 132005

Accepted after revision:

September 222006

SUPPORT STATEMENT

A. Koch was supported by grants from the Deutsche

Forschungsgemeinschaft (DFG), Bonn, Germany (K0-1788/3-1); the Lise-Meitner-Habilitations-Program of the Ministerium für Schule, Wissenschaft und Forschung des Landes Nordrhein Westfalen (446037.5), Düsseldorf, Germany; Bayer Ltd, Leverkusen, Germany; and Bayer Research Centres in the UK (Bayer PLC, Stoke Court, UK) and Kyoto (Bayer Yakuhin Ltd, Kyoto, Japan).

European Respiratory Journal Print ISSN 0903-1936

Online ISSN 1399-3003 
cytokine profiles and reported a Tc1-like immune response of peripheral blood CD4+ T-cells with increased interferon (IFN)- $\gamma$ expression in subjects with COPD. Interestingly, as well as producing the cytokines IFN- $\gamma$ and interleukin-2, Tc1-cells also express the chemokine receptor $\mathrm{CXCR}_{3}$ and its ligand CXCL10 during smoking-induced T-cell activation [1, 9]. $\mathrm{CXCR}_{3}$ is one of the chemokine receptors induced predominantly on cytotoxic Tc1-cells [9]. Moreover, the release of $\mathrm{CXCR}_{3}$-activating chemokines attracts Tc1-cells into the lungs, causing IFN- $\gamma$ to induce more $\mathrm{CXCR}_{3}$ ligands. This results in a self-perpetuating loop that may lead to accumulation of activated Tc1-cells in the peripheral lung [9]. Indeed, a study by SAETTA et al. [1] on smokers with COPD showed increased numbers of $\mathrm{CXCR}_{3}+\mathrm{T}$-cells in both epithelium and submucosa of the airways compared with controls, indicating a Tc1-like inflammatory airway response in COPD. In contrast to the findings in lung parenchyma, LECKIE et al. [10] were unable to confirm this finding in induced sputum, where the percentage of CD8+ lymphocytes expressing $\mathrm{CXCR}_{3}$ was lower than in blood from subjects with COPD. This indicates that different compartments should be analysed separately since induced sputum does not necessarily reflect the situation in lung parenchyma or in peripheral blood.

The prototypic co-stimulatory molecule CD28 is a receptor involved in the regulation of $\mathrm{T}$-cell activation and in the generation of antigen-primed cells [11]. A substantial number of other co-stimulatory molecules and their ligands have been identified in recent years [12]. EKBERG-JANSSON et al. [12] reported a greater proportion of T-lymphocyte activation markers (human leukocyte antigen (HLA)-DR, CD26+, CD54+, CD69+) in bronchoalveolar lavage (BAL) fluid compared with blood in nonsmokers. Moreover, GLADER et al. [7] showed a clear correlation between expression of the activation marker CD69 on CD4+ T-cells and lung function (forced expiratory volume in one second (FEV1)) in current smokers with and without COPD, indicating smoking-induced impairment of T-cell activation.

To promote the extravasation of peripheral blood lymphocytes, endothelial cells are known to secrete chemokines, such as monocyte chemotactic protein (MCP)-1, which guide lymphocytes to inflammatory sites or secondary lymphoid organs and into distinct compartments within the lung [13]. However, little is known about the modulatory effects of cigarette smoking on the expression of $\mathrm{CXCR}_{3}$ and on the chemotactic activity of peripheral blood CD8+ T-lymphocytes to MCP-1 in this context.

Human CD8+ T-cells with a CD27+/CD45RA- phenotype are memory cells of low cytotoxicity, while those with a CD27-/ CD45RA+ phenotype are cytotoxic effector cells [14]. An increased infiltration of cytotoxic CD8+ T-lymphocytes into the central airways [15] and the lung parenchyma [16] and increased numbers of these cells in sputum samples [17] have been reported in COPD patients.

Therefore, in the present study, the authors examined the potential role of cigarette smoking in modulating the surface activation antigen CD28, the numbers of cytotoxic effector Tcells (CD27-/CD45RA+) and the expression of the Tc1-specific chemokine receptor $\mathrm{CXCR}_{3}$ surface antigen on peripheral blood $\mathrm{CD}^{+} \mathrm{T}$-lymphocytes. The chemotactic activity of CD8+ T-cells to MCP-1 was also studied and nonsmokers were compared with smokers with and without COPD.

\section{MATERIALS AND METHODS Subjects}

The study population consisted of 13 healthy nonsmokers, 14 current smokers without respiratory symptoms or airflow limitation and 12 current smokers with respiratory symptoms and moderate to severe airflow limitation [18] (table 1).

None of the subjects were using oral or inhaled corticosteroids, receiving immunosuppressive treatment, reported any other serious illness or acute viral disease during the 2 months preceding the test or had tuberculosis, parasite infections, history of allergies or asthma. The nonsmokers and smokers $(\geqslant 10$ pack-yrs and $\leqslant 40$ pack-yrs) with normal chest radiographic and spirometry findings were selected from a population that had undergone an annual health check-up. COPD was diagnosed according to the criteria recommended by the National Institutes of Health/World Health Organization workshop summary [19]. The smokers with COPD ( $\geqslant 10$ pack-yrs) had a history of cough with sputum production and/or dyspnoea on most days of the month for $\geqslant 3$ months a year during $>2$ yrs before the study. They also presented airflow limitation on spirometry (FEV1/forced vital capacity $<70 \%$ and FEV $1<80 \%$ of predicted value), as defined by the Global Initiative for Chronic Obstructive Lung Disease initiative $[18,19]$. The airflow limitation in these patients was irreversible, as shown by a negative immediate response to inhalation of $200 \mu \mathrm{g}$ of albuterol ( $\leqslant 12 \%$ reversibility). Their pulmonary function had been stable for several months under observation. There was no statistical difference in cigarette smoke exposure and age between smokers with and without COPD. The study was approved by the ethics committee of the University of Cologne, Cologne, Germany.

\begin{tabular}{|c|c|c|c|}
\hline \multirow[t]{2}{*}{ TABLE 1} & \multicolumn{3}{|c|}{$\begin{array}{l}\text { Characteristics of healthy nonsmokers, smokers } \\
\text { and subjects with chronic obstructive pulmonary } \\
\text { disease (COPD) }\end{array}$} \\
\hline & Nonsmokers & Smokers & $\begin{array}{l}\text { Smokers with } \\
\text { COPD }\end{array}$ \\
\hline Subjects $n$ & 13 & 14 & 12 \\
\hline Age yrs & $48.3 \pm 2.7$ & $47.4 \pm 4.3$ & $56.0 \pm 2.1$ \\
\hline Male:female & $7: 6$ & $8: 6$ & $7: 5$ \\
\hline FEV $1 \%$ pred & $100.6 \pm 3.1$ & $104.5 \pm 3.6$ & $46.7 \pm 3.9^{\#}$ \\
\hline $\begin{array}{l}\mathrm{FEV}_{1 / \mathrm{FVC}} \% \\
\text { pred }\end{array}$ & $84.3 \pm 1.5$ & $84.7 \pm 2.2$ & $54.3 \pm 2.7^{\#}$ \\
\hline FVC \% pred & $100.9 \pm 2.8$ & $106.1 \pm 4.5$ & $68.8 \pm 4.4^{\#}$ \\
\hline RV/TLC $\%$ pred & $28.9 \pm 1.8$ & $33.6 \pm 3.4$ & $66.4 \pm 2.8^{\#}$ \\
\hline RV \% pred & $110.0 \pm 7.0$ & $118.6 \pm 11.1$ & $211.5 \pm 8.3^{\#}$ \\
\hline IC \% pred & $86.6 \pm 3.2$ & $89.4 \pm 7.4$ & $60.7 \pm 6.0^{\#}$ \\
\hline Pack-yrs & & $33.8 \pm 0.5$ & $35.3 \pm 2.8$ \\
\hline
\end{tabular}




\section{Pulmonary function study}

Spirometric parameters and lung volumes were measured according to the recommendations of the American Thoracic Society [20] using a body plethysmograph (Masterlab; Viasys, Würzburg, Germany) and were expressed as a percentage of predicted using the prediction formula of GOLDMAN and BeCKLAGE [21] (table 1).

\section{Isolation of CD8+ T-lymphocytes from peripheral blood}

Peripheral venous blood from all subjects was drawn after obtaining informed consent. Aliquots were submitted to the laboratory for differential white blood cell count (table 2). Peripheral blood mononuclear cells were separated from acid citrate dextrose venous blood and obtained after Ficoll-Paque gradient centrifugation. T-cells were isolated from mononuclear cells by immunomagnetic depletion of CD14, CD16, CD56 and HLA Class IIDR/DP (B-cells, natural killer-cells, monocytes, granulocytes) with a T-cell isolation kit (Dynal Biotech, Hamburg, Germany) by negative selection. The selected cells were routinely $\geqslant 95 \% \mathrm{CD} 3+$. To obtain purified CD8+ T-cells, the present authors used the CD8+ isolation kit (Dynal Biotech) for rapid immunomagnetic separation of CD4+ T-cells and CD8+ T-lymphocytes according to the manufacturer's instructions. The purity of the CD8+ T-cells determined by flow cytometry was routinely $\geqslant 98 \%$.

\section{CD8+ T-cell chemotaxis assay}

The chemotaxis assay was performed using a 96-well microchamber, as previously described elsewhere [22]. The chemoattractant MCP-1 was diluted in RPMI 1640 medium containing $1 \%$ foetal calf serum (FCS) to final concentrations

\begin{tabular}{|c|c|c|c|}
\hline \multirow[t]{2}{*}{ TABLE 2} & \multicolumn{3}{|c|}{$\begin{array}{l}\text { Peripheral blood cell counts in nonsmokers, } \\
\text { smokers and subjects with chronic obstructive } \\
\text { pulmonary disease (COPD) }\end{array}$} \\
\hline & Nonsmokers & Smokers & Smokers with COPD \\
\hline Subjects $n$ & 13 & 14 & 12 \\
\hline \multicolumn{4}{|l|}{ Leukocytes } \\
\hline $10^{3} \cdot \mu \mathrm{L}^{-1}$ & $6.5 \pm 0.3$ & $7.8 \pm 0.8$ & $8.8 \pm 0.7$ \\
\hline \multicolumn{4}{|l|}{ Lymphocytes } \\
\hline $10^{3} \cdot \mu \mathrm{L}^{-1}$ & $2.0 \pm 0.1$ & $2.3 \pm 0.3$ & $1.9 \pm 0.1$ \\
\hline Leukocytes \% & $31.3 \pm 2.3$ & $29.7 \pm 1.5$ & $22.9 \pm 1.5^{\#}$ \\
\hline \multicolumn{4}{|l|}{ Eosinophils } \\
\hline $10^{3} \cdot \mu \mathrm{L}^{-1}$ & $0.16 \pm 0.03$ & $0.15 \pm 0.02$ & $0.24 \pm 0.05$ \\
\hline Leukocytes \% & $2.47 \pm 0.4$ & $2.01 \pm 0.2$ & $2.85 \pm 0.4$ \\
\hline \multicolumn{4}{|l|}{ Neutrophils } \\
\hline $10^{3} \cdot \mu \mathrm{L}^{-1}$ & $3.79 \pm 0.3$ & $4.67 \pm 0.5$ & $5.79 \pm 0.5^{\circ}$ \\
\hline Leukocytes \% & $57.5 \pm 26$ & $59.9 \pm 1.9$ & $65.2 \pm 1.7^{\bullet}$ \\
\hline \multicolumn{4}{|l|}{ Monocytes } \\
\hline $10^{3} \cdot \mu \mathrm{L}^{-1}$ & $0.4 \pm 0.03$ & $0.4 \pm 0.06$ & $0.5 \pm 0.06$ \\
\hline Leukocytes \% & $5.63 \pm 0.36$ & $5.16 \pm 0.50$ & $6.12 \pm 0.46$ \\
\hline \multicolumn{4}{|l|}{ Basophils } \\
\hline $10^{3} \cdot \mu \mathrm{L}^{-1}$ & $0.05 \pm 0.007$ & $0.06 \pm 0.009$ & $0.07 \pm 0.015$ \\
\hline Leukocytes \% & $0.90 \pm 0.12$ & $0.92 \pm 0.13$ & $0.92 \pm 0.13$ \\
\hline
\end{tabular}

Data are presented as mean $\pm \mathrm{SD}$, unless otherwise stated. ${ }^{*}: \mathrm{p}<0.01$ versus smokers and nonsmokers using the Newman-Keuls test; $\uparrow: p<0.05$ versus nonsmokers using the Newman-Keuls test. of $0.125 \mu \mathrm{g} \cdot \mathrm{mL}^{-1}$ and $0.25 \mu \mathrm{g} \cdot \mathrm{mL}^{-1}$. Then, $50 \mu \mathrm{L}$ were placed in the lower chamber. Purified CD8+ T-cells were resuspended at a concentration of $5 \cdot 10^{6}$ cells $\cdot \mathrm{mL}^{-1}$ in RPMI / $1 \%$ FCS and incubated for $1 \mathrm{~h}$ at $37^{\circ} \mathrm{C}$ in an atmosphere containing $5 \% \mathrm{CO}_{2}$. A cell suspension of $50 \mu \mathrm{L}\left(2.5 \cdot 10^{5}\right.$ cells) was added to the upper part of the chamber separated from the lower chamber by a 5 - $\mu \mathrm{m}$-pore-size polycarbonate, polyvinylpyrrolidone-free filter (Applichem, Darmstadt, Germany) coated with mouse type IV collagen (BD Biosciences, Bedford, England). The Boyden chamber was incubated for $120 \mathrm{~min}$ at $37^{\circ} \mathrm{C}$ in an atmosphere containing $5 \% \mathrm{CO}_{2}$. The filters were carefully removed, fixed in 70\% methanol and stained with Diff-Quick (Dade Behring, Newark, NJ, USA). After removal of nonmigrated cells from the upper surface, migrated and adhered cells on the lower surface of the membrane were counted by measuring their area with a defined phase contrast microscope (Phase Contrast ELWD 0.3 (OD $75 \mathrm{~mm}$ ); Nikon, Cambridge, MA, USA) with a $10 \times 10$ field diagram. The number in each field was calculated. CD8+ T-lymphocyte migration was quantified by counting the total number of cell migrations completely through the filter in duplicate samples. The number of migrated cells in the negative control, which reflects spontaneous migration, was subtracted from the number of migrated cells in the samples.

\section{Four-colour fluorescence-activated cell sorting analysis and gating strategy}

Whole blood $\left(100 \mu \mathrm{L} \cdot\right.$ tube $\left.^{-1}\right)$ was incubated with $\mathrm{CXCR}_{3}+-$ conjugated fluorescein-isothiocyanat (FITC)-Antibody (Ab) (R\&D Systems, Wiesbaden, Germany), CD4+-conjugated FITC-Ab, CD45RA+-conjugated FITC-Ab, CD28+-conjugated $\mathrm{PE}-\mathrm{Ab}, \mathrm{CD} 27+-$ conjugated phycoerythrin (PE)-Ab, CD3+-conjugated phycoerythrin and texas red (ECD)-Ab or CD8+conjugated phycoerythrin and cyanin (PC)5-Ab (Beckman Coulter, Krefeld, Germany) for $20 \mathrm{~min}$ in darkness at room temperature according to the study protocol. FITC-, PE- and PC5-conjugated isotype-immunoglobulin (Ig)G control and isotype-IgG-ECD control were purchased from Beckman Coulter. The red blood cells were lysed using lysing solution (Beckman Coulter) for $20 \mathrm{~min}$. The samples were then vortexed and centrifuged for $5 \mathrm{~min}$ at $415 \times g$ and $4{ }^{\circ} \mathrm{C}$. The supernatant was discarded and the pellet resupended in $1 \mathrm{~mL}$ PBS. A total of 50,000 cells were analysed by flow cytometry in each test. Cells were initially gated on the basis of forward and side scatter characteristics, with gates set to remove debris and platelets. Results were expressed as the percentage of cells exhibiting positive fluorescence.

\section{Data analysis}

Data are reported as mean \pm SEM. A Kruskal-Wallis one-way ANOVA was used to evaluate significant differences between groups and, when significance was found, post hoc betweengroup analysis was performed with the Newman-Keuls test. A p-value $<0.05$ was considered significant.

\section{RESULTS}

\section{Peripheral blood cell counts}

As table 2 shows, there was a significant increase in peripheral blood neutrophils (expressed as absolute neutrophil counts and as percentage of all leukocytes) in smokers with COPD compared with nonsmokers $(\mathrm{p}<0.05)$. There was a decrease in 


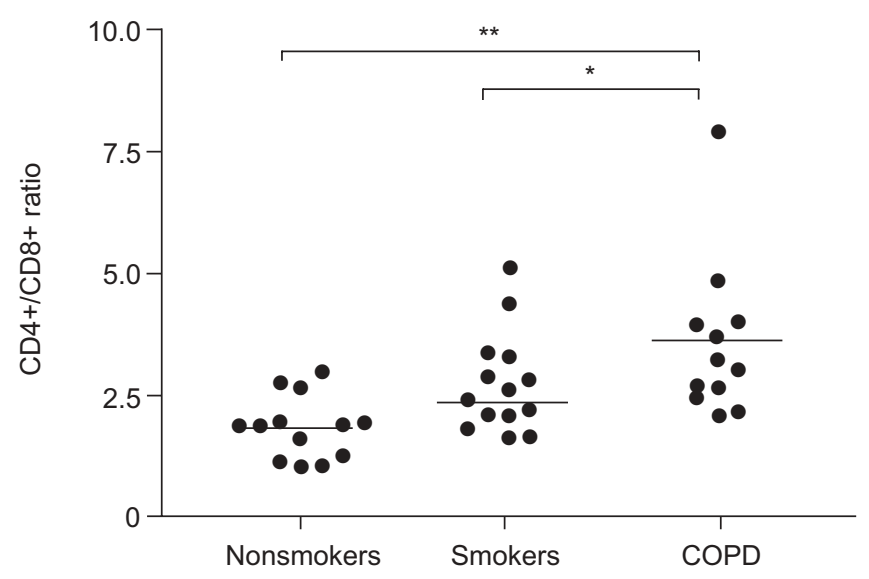

FIGURE 1. Individual values for CD4+/CD8+ ratios of peripheral blood T-lymphocytes. The data presented are derived from separate experiments using cells from 13 nonsmokers, 14 smokers without chronic obstructive pulmonary disease (COPD) and 12 smokers with COPD. There was a significant increase in $\mathrm{CD} 4+/ \mathrm{CD} 8+$ ratio in smokers with COPD compared with smokers without COPD and nonsmokers, while no difference was found between smokers without COPD and nonsmokers. Median values are represented by $\ldots$. ${ }^{*}: p<0.05 ;{ }^{*}: p<0.01$.

total lymphocytes in smokers with COPD compared with smokers without COPD and controls, which was statistically significant when expressed as a percentage of all leukocytes $(\mathrm{p}<0.01)$ but not as absolute lymphocyte counts.

\section{Total count and ratio of CD4+ and CD8+ T-lymphocytes in peripheral blood}

There was a significant increase in the percentage of CD4+/ CD3+ T-cells and a significant decrease in the percentage of CD8+/CD3+ T-lymphocytes in smokers with COPD (CD4+: $73.4 \pm 2.1 \%, \mathrm{p}<0.01 ; \mathrm{CD} 8+: 22.7 \pm 1.6 ; \mathrm{p}<0.01)$ compared with nonsmokers (CD4+: $60.5 \pm 2.0 \%, \mathrm{CD} 8+: 34.2 \pm 2.0)$ and smokers without COPD (CD4+: $65.9 \pm 2.5 \%, \mathrm{p}<0.05$; CD8+: $29.8 \pm 2.1$; $\mathrm{p}<0.05$; graph not shown). As figure 1 shows, these smokingindependent changes were also found in the $\mathrm{CD} 4+/ \mathrm{CD} 8+$ ratio in smokers with COPD $(3.5 \pm 0.4)$ compared with smokers without COPD $(2.4 \pm 0.3 ; \mathrm{p}<0.05)$ and nonsmokers $(1.9 \pm 0.2$; $\mathrm{p}<0.01)$.

\section{Th/Th2 differentiation of CD8+ T-lymphocytes in peripheral blood}

Figures $2 \mathrm{a}, \mathrm{b}$ and $\mathrm{c}$ show original flow cytometry analyses based on PC-5-conjugated CD8+ T-lymphocytes and FITCconjugated $\mathrm{CXCR}_{3}+\mathrm{T}$-cell populations from a nonsmoker and a smoker without COPD and from a smoker with COPD. Figure $2 \mathrm{~d}$ summarises the data of parallel stainings for ECDconjugated CD3+ T-cells and PC5-conjugated CD8+ and FITCconjugated $\mathrm{CXCR}_{3}+$ dot blots and shows flow cytometry analysis results of $\mathrm{CXCR}_{3}+$ peripheral blood T-lymphocytes expressed as a percentage of total CD8+ T-cells. All events above the isotype control were defined as $\mathrm{CXCR}_{3}+$.

There was a significant increase in the percentage of $\mathrm{CXCR}_{3}+$ / CD8+ T-lymphocytes in smokers with COPD $(70.1 \pm 1.8 \%)$ compared with nonsmokers $(60.7 \pm 2.5 \%$; $\mathrm{p}<0.05)$ and smokers without COPD $(60.9 \pm 2.6 \% ; \mathrm{p}<0.05)$. In contrast, there was no statistical difference between $\mathrm{CXCR}_{3}+/ \mathrm{CD} 8+\mathrm{T}$-lymphocytes in smokers without COPD and nonsmokers ( $\mathrm{p}>0.05$, nonsignificant (NS)). This indicates that the increased number of $\mathrm{CXCR}_{3}+$ CD8+ T-cells in COPD is smoking-independent (fig. $2 \mathrm{~d}$ ). The percentage of positive cells in these subsets stained with mouse $\operatorname{IgG} \mathrm{mAb}$ was $<1 \%$.

\section{Activation of CD8+ T-lymphocytes in peripheral blood}

CD28 is a co-stimulatory receptor involved in the regulation of T-cell activation [11]. Staining for ECD-conjugated CD3+ Tcells, PC5-conjugated CD8+ and PE-conjugated CD28+ was performed on dot blots from a nonsmoker, a smoking individual and from a subject with COPD, as shown in figures $3 a, b$ and c. Summarised individual values of flow cytometry results of CD28+ peripheral blood T-lymphocytes were expressed as percentages of total CD8+ T-cells. As figure $3 \mathrm{~d}$ shows, there was a significant increase in the percentage of CD28+/CD8+ T-cells in smokers without COPD $(72.9 \pm 3.7 \% ; \mathrm{p}<0.05)$ and in subjects with COPD $(75.4 \pm 3.9 \%$; $\mathrm{p}<0.05)$ compared with nonsmokers $(61.0 \pm 2.7 \%)$. In contrast, there was no significant difference between CD28+/CD8+ Tlymphocytes in smokers with and without COPD ( $p>0.05$, NS). This indicates that the activation of CD8+ T-cells in both groups could be smoking-related. The percentage of positive cells in these subsets stained with mouse IgG $\mathrm{mAb}$ was $<1 \%$.

\section{Chemotactic activity of CD8+T-lymphocytes to MCP-1}

There was no significant difference in spontaneous migration of peripheral blood CD8+ T-lymphocytes between groups (smokers: $1.58 \pm 0.23$; COPD: $1.89 \pm 0.54$; nonsmokers: $1.79 \pm 0.15$; NS for all).

However, as figure 4 shows, there was decreased chemotactic activity of CD8+ T-lymphocytes to MCP-1 at a concentration of $0.125 \mu \mathrm{g} \cdot \mathrm{mL}^{-1}$ in smokers without COPD $(6.3 \pm 0.8)$ and in smokers with COPD $(6.7 \pm 0.7)$ compared with nonsmokers $(9.9 \pm 1.0 ; \mathrm{p}<0.05)$. There was no statistical difference between smokers with and without COPD indicating a smokingdependent decreased chemotactic activity of CD8+ T-cells to MCP-1.

At the higher concentration of $0.25 \mu \mathrm{g} \cdot \mathrm{mL}^{-1}$, the migration of peripheral blood CD8+ T-lymphocytes to MCP-1 was not statistically different between groups: smokers without COPD $(7.1 \pm 1.0)$ and smokers with COPD $(8.8 \pm 0.8)$ compared with nonsmokers $(10.7 \pm 1.4 ; \mathrm{p}>0.05)$.

\section{Cytotoxic/effector phenotype of peripheral blood CD8+ T- lymphocytes}

In the present study the authors attempted to clarify smokinginduced immunomodulatory effects on cytotoxic effector CD8+ T-cells (CD27-/CD45RA+) using a parallel colour flow cytometric analysis, including PC5-conjugated CD8+, FITC-conjugated CD45RA+ and PE-conjugated CD27+ dot blots (figs. 5a, b and c). In figure 5d, CD27-/ CD45RA+ peripheral blood CD8+ T-lymphocytes are expressed as the percentage of total CD8+ T-cells from individual patients. The data presented are derived from separate experiments using cells from 13 nonsmokers, 14 smokers without and 12 smokers with COPD. There was a significant increase in the percentage of CD27-/ CD45RA+ T-lymphocytes in relation to total CD8+ T-cells from smokers without COPD $(18.4 \pm 2.4 \%)$ and from smokers with COPD (23.5 \pm 4.3$)$ compared with nonsmokers (8.4 \pm 1.2 ; 

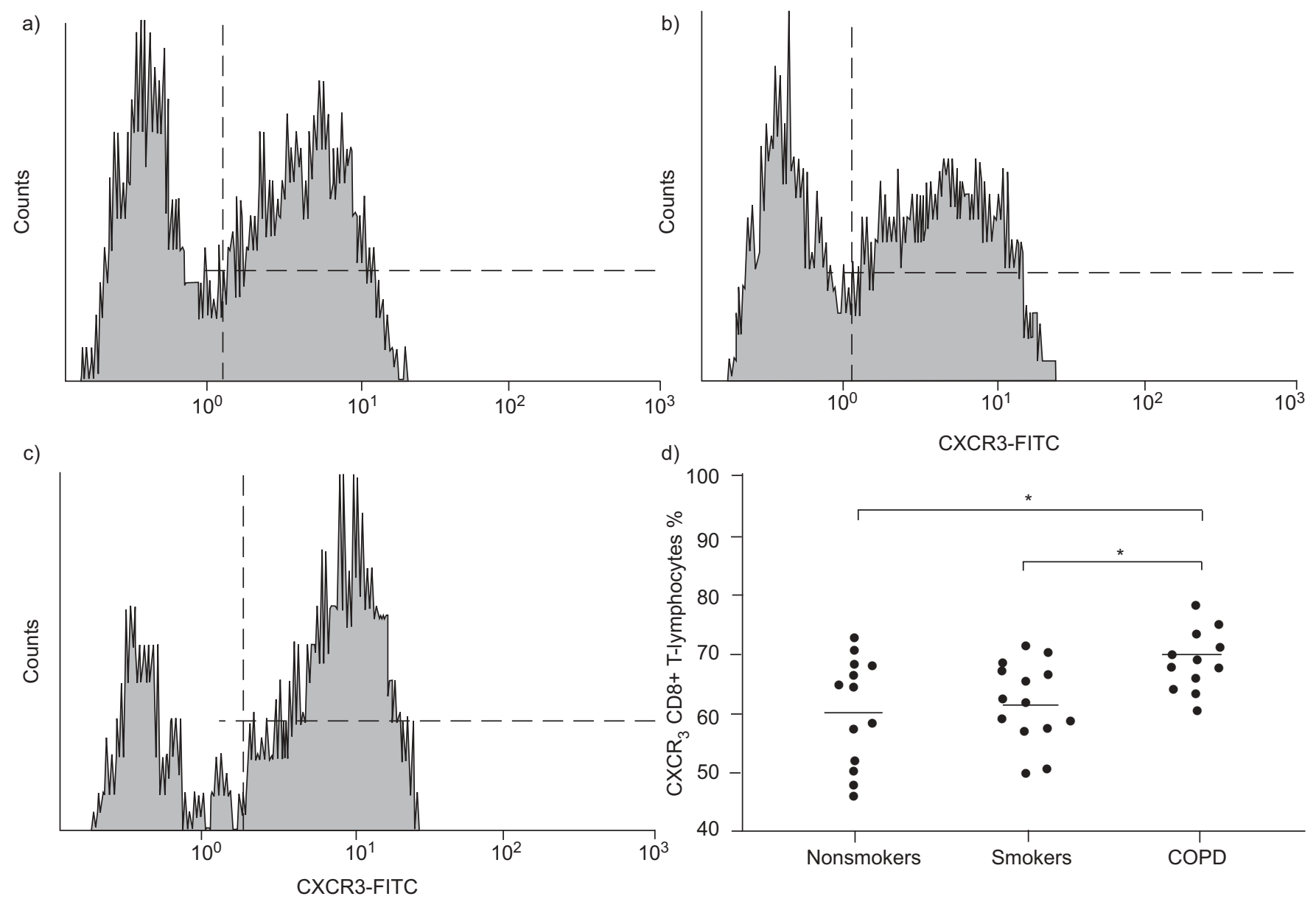

FIGURE 2. a-c) Representative original fluorescence-activated cell sorting (FACS) analyses of ECD-conjugated CD3+ T-cells and PC-5-conjugated CD8+ and FITCconjugated CXCR3+ populations of a nonsmoking individual (a; CD3+/CD8+57.5\%), a smoking individual (b; CD3+/CD8+58.4\%) and a subject with chronic obstructive pulmonary disease (COPD) (c; CD3+/CD8+ 70.2\%). d) Individual results of FACS analysis of ECD-conjugated CD3+ T-cells and PC5-conjugated CD8+ and FITC-conjugated $\mathrm{CXCR}_{3}+$ dot blots of 13 nonsmokers, 14 smokers without and 12 smokers with COPD. There was a significant increase in the percentage of $\mathrm{CXCR}+\mathrm{T}$-lymphocytes in relation to total CD8+ T-cells in smokers with COPD compared with nonsmokers and smokers without COPD. In contrast, there was no significant difference between smokers without COPD and nonsmokers. Median values are represented by —. . * $p<0.05$.

$\mathrm{p}<0.05$ versus smokers; $\mathrm{p}<0.01$ versus COPD). This indicates a smoking-related increase in cytotoxicity of CD8+ T-cells. The percentage of positive cells in these subsets stained with mouse IgG $\mathrm{mAb}$ was $<1 \%$.

\section{DISCUSSION}

In the present study the authors found a higher number of CD4+ T-cells, a lower number of CD8+ T-lymphocytes and a higher $\mathrm{CD} 4+/ \mathrm{CD} 8+$ ratio in the peripheral blood of smokers with COPD compared with smokers without airflow limitation and nonsmokers (fig. 1). As table 2 shows, there was no difference in total lymphocyte counts expressed in absolute values between all groups. This compartment-specific decrease in CD8+ T-lymphocytes is in contrast to previous findings of increased CD8+ T-cell populations in lung parenchyma [23], pulmonary arteries [23], peripheral airways [24] and induced sputum [25] of smokers with COPD. This was underlined by the fact that the CD4+/CD8+ ratio was significantly lower in induced sputum from smokers with COPD compared with smokers without COPD and nonsmokers [25]. However, a parallel T-cell subset analysis in the airways and in peripheral blood from smokers with and without COPD is needed to clarify this point. The smoking-independent results of the present study in COPD may be consistent with a study by AMADORI et al. [26], who presented evidence explaining why smokers may develop COPD and suggested that individuals with a genetically determined increase in the CD8+ population might be more susceptible to further CD8+ T-cell abnormalities [27]. This increased susceptibility may in turn be enhanced by cigarette smoking [15] or repeated virus infections [28], inducing an abnormal inflammatory response contributing to the pathogenesis of COPD. In contrast to the present authors' results, de JoNG et al. [29] found a lower CD4+/CD8+ ratio in peripheral blood from COPD patients compared with nonsmoking healthy control subjects. However, in that particular study all COPD patients were nonsmokers [29]. KIM et al. [6] studied subgroups of smokers with COPD and reported that a reduced $D \mathrm{~L}, \mathrm{CO} / V \mathrm{~A}$ was correlated with a lower proportion of peripheral blood CD8+ T-lymphocytes and a higher CD4+/ CD8+ ratio compared to COPD patients with a normal DL,CO/ $V$ A. This suggests that T-lymphocyte abnormalities might be involved in the pathogenesis of airflow limitation. 

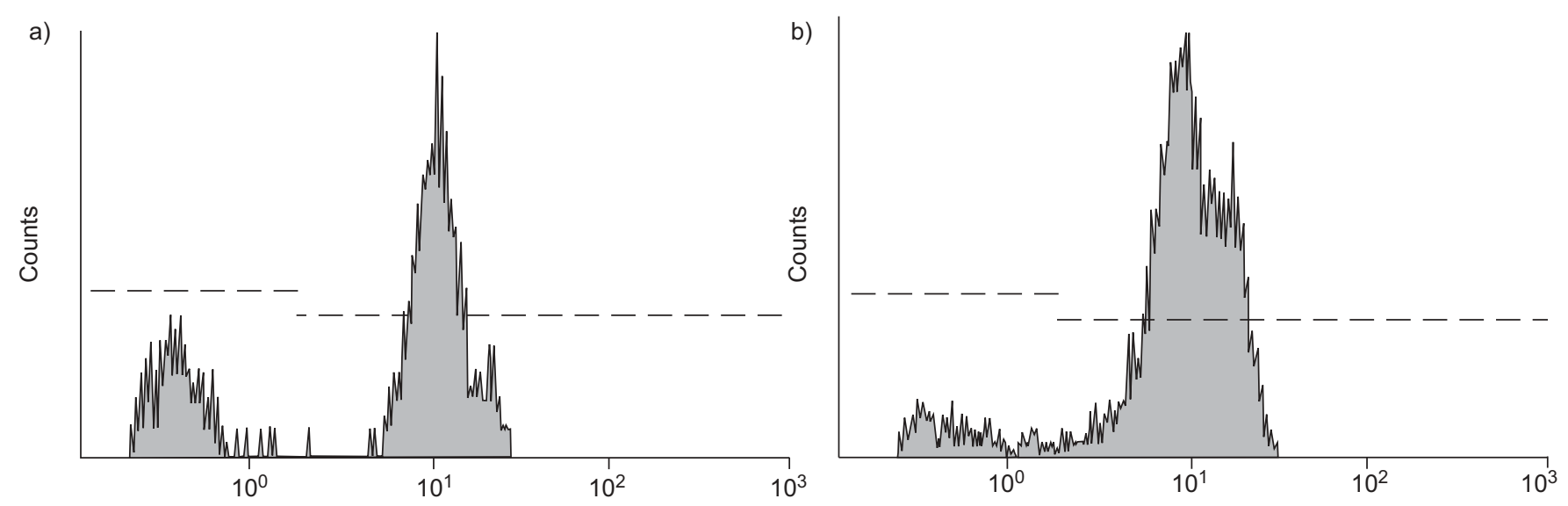

c)

d)
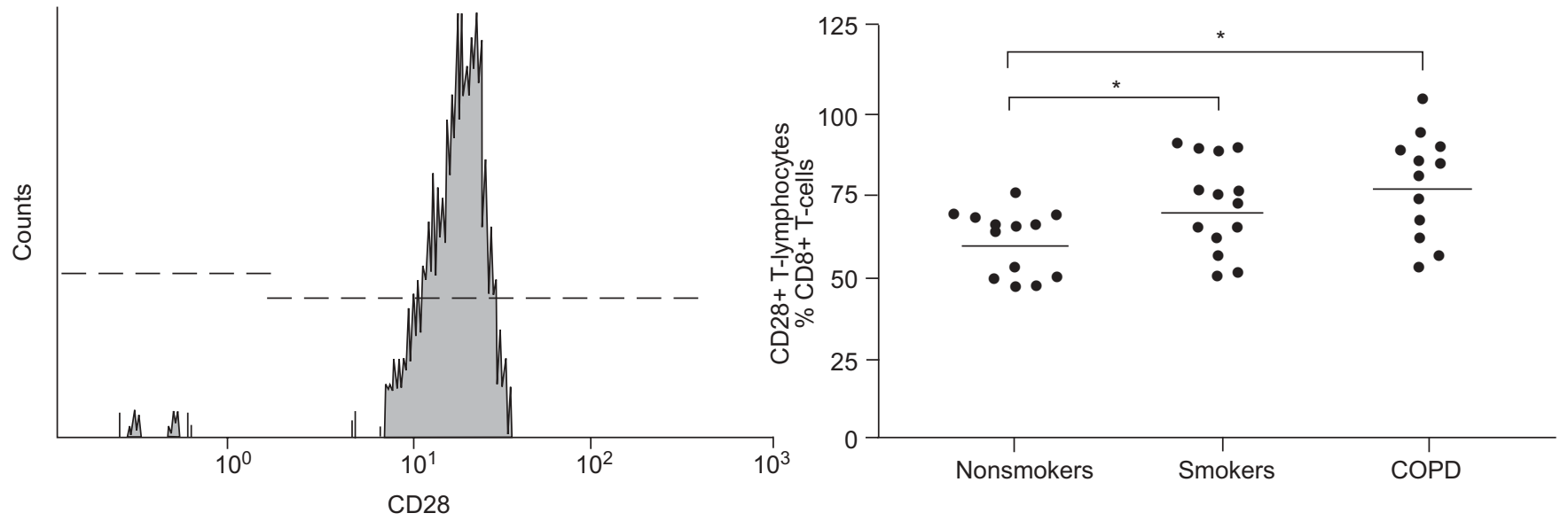

FIGURE 3. a-c) Representative original fluorescence-activated cell sorting (FACS) analyses based on ECD-conjugated CD3+/PC5-conjugated CD8+ and PE-conjugated CD28+ populations of a nonsmoker (a) and smokers without (b) and with chronic obstructive pulmonary disease (COPD; C). d) CD28+ peripheral blood T-lymphocytes expressed as a percentage of CD8+ T-cells of 13 nonsmokers, 14 smokers without and 12 smokers with COPD. There was a significant increase in the percentage of CD28+ T-lymphocytes in smokers with and without COPD compared with nonsmokers, while no differerence was found between smokers with and without COPD. Median values are represented by _. * ${ }^{*}: p<0.05$.

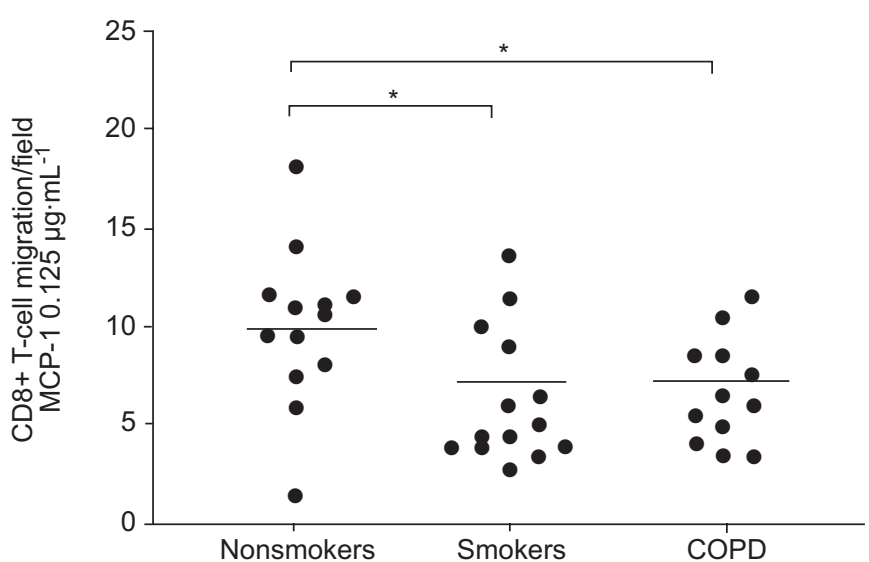

FIGURE 4. CD8+ T-cell chemotaxis assay of monocyte chemotactic protein (MCP)-1 $\left(0.125 \mu \mathrm{g} \cdot \mathrm{mL}^{-1}\right)$ stimulated peripheral blood T-lymphocytes expressed as CD8+ T-lymphocyte migration/field using cells from 13 nonsmokers, 14 smokers without and 12 smokers with chronic obstructive pulmonary disease (COPD). There was a significant decreased chemotactic activity of CD8+ T-lymphocytes to MCP-1 from smokers with and without COPD compared with nonsmokers but no statistical difference between smokers with and without COPD. Median values are represented by —. * $: p<0.05$.
Recent evidence suggests that CD8+ T-cells implicated in COPD are of the Tc1 phenotype [30]. Indeed, in the present study the authors were able to demonstrate a smokingindependent increase in the Tc1-specific $\mathrm{CXCR}_{3}+$ surface antigen of peripheral blood CD8+ T-lymphocytes in smokers with COPD compared with smokers without airflow limitation (fig. 2). The release of $\mathrm{CXCR}_{3}$-activating chemokines attracts Tc1-cells into the lungs, followed by expression of IFN- $\gamma$, which may lead to accumulation of activated Tc1-cells in the peripheral lung [30]. The specificity of this effect was confirmed by SAETTA et al. [1], who found increased numbers of $\mathrm{CXCR}_{3}+\mathrm{T}$-cells in both epithelium and submucosa of the airways in smokers with COPD compared with controls. Interestingly, TZANAKIS et al. [25] noted a decrease in IFN- $\gamma$ producing CD8+ T-cells (Tc1) in sputum from smokers with COPD compared with smokers and nonsmokers. This is consistent with the findings of LECKIE et al. [10], who found a lower percentage of CD8+ T-lymphocytes expressing $\mathrm{CXCR}_{3}+$ in induced sputum from COPD patients compared with nonsmokers. This indicates that sputum results do not always reflect changes of $\mathrm{T}$-cell phenotype seen in the airways and in peripheral blood. XIE et al. [9] demonstrated that $\mathrm{CXCR}_{3}$ played a critical role in T-cell transmigration to sites of inflammation. 


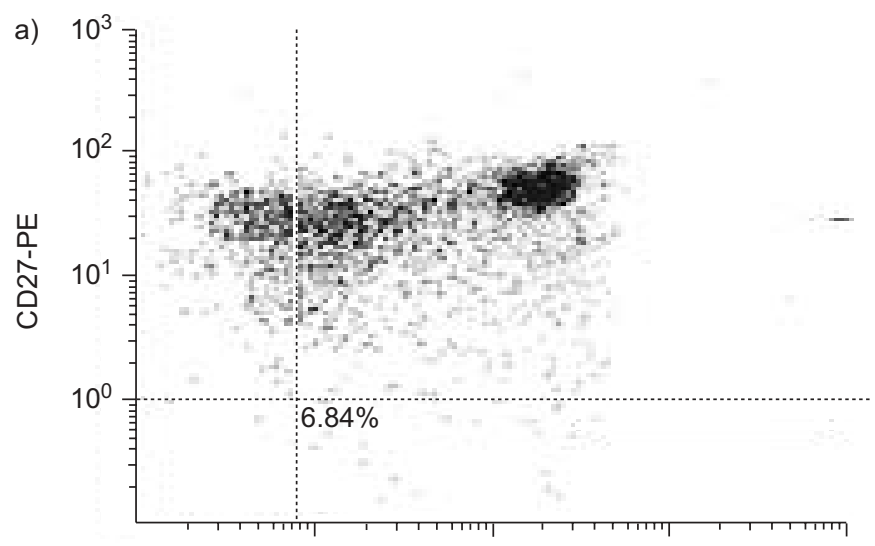

b)
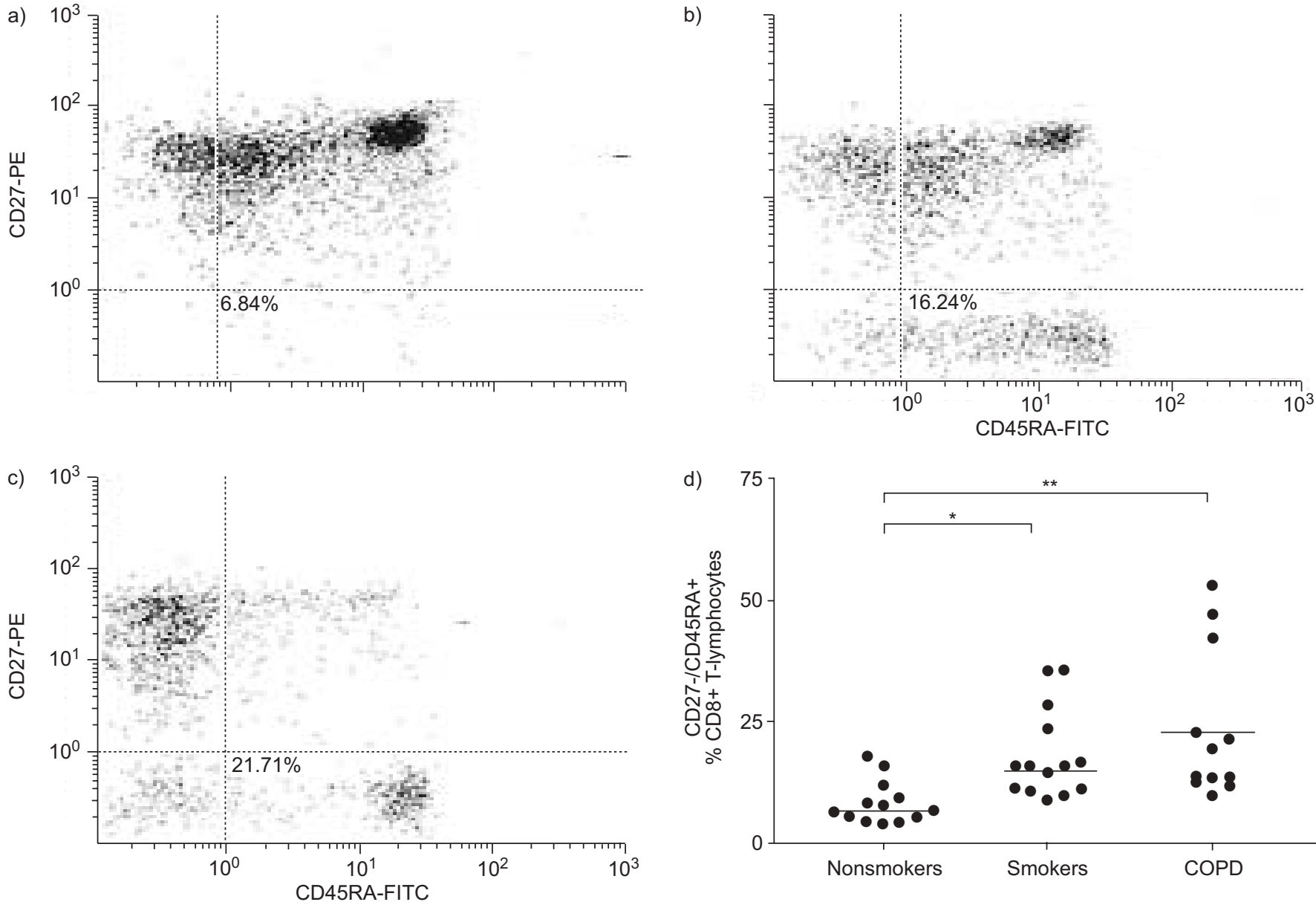

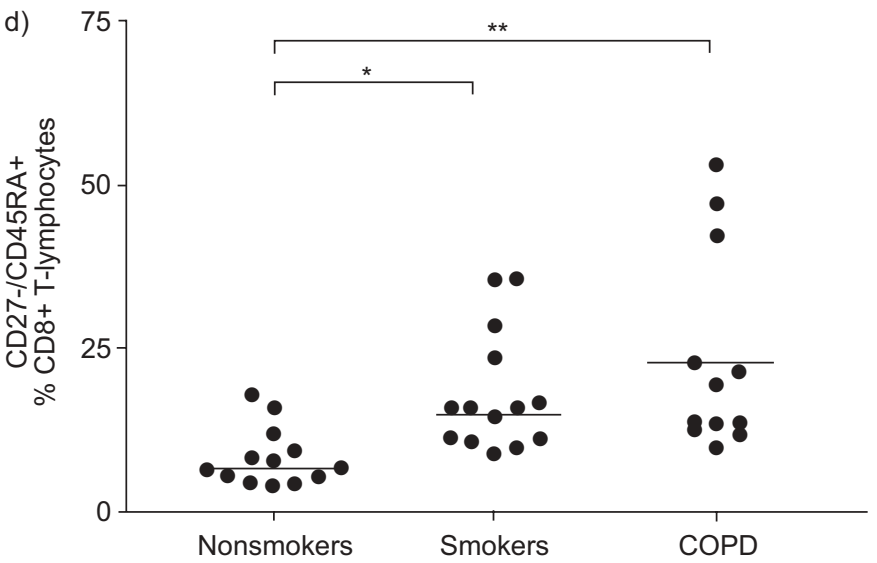

FIGURE 5. a-c) Representative original fluorescence-activated cell-sorting (FACS) analyses of PC5-conjugated CD8+ and PE-conjugated CD27+ T-cells and FITCconjugated CD45RA+ T-cell population from a nonsmoker (a), a smoker without (b) and a smoker with chronic obstructive pulmonary disease (COPD; c). d) Summary of the individual values of parallel colour stainings of CD27- and CD45RA+ peripheral blood T-lymphocytes expressed as a percentage of CD8+ T-cells from 13 nonsmokers, 14 smokers without and 12 smokers with COPD. There was a significant increase in the percentage of CD27-/CD45RA+ T-lymphocytes in relation to total CD8+ T-cells of smokers with and without COPD compared with nonsmokers. In contrast, there was no statistical difference between CD27-/CD45RA+ T-lymphocytes in relation to CD8+ Tcells in smokers with and without COPD. Median values are represented by __. ${ }^{*}: p<0.05 ; * *: p<0.01$.

These findings provide further evidence that dysregulation of Tc1-agonist chemokines and their cognate receptors, such as $\mathrm{CXCR}_{3}$, might contribute to the immunopathology of COPD [31] in a smoking-independent manner.

Previous studies have not comprehensively analysed different activation markers on T-cells distinguishing between expression on CD4+ and CD8+ T-cells. Recently, GLADER et al. [7] demonstrated that the expression of the surface activation marker CD69 on CD4+ T-cells in smokers and COPD patients correlated with lung function measured as $\mathrm{FEV} 1 \%$ pred, indicating a protective effect for smokers. Previous studies reported that no differences were found in CD25+ [8], CD69+ [10] and CD45RO+ [29] surface activation marker expression of T-cells in peripheral blood of COPD patients and of healthy subjects. EKBERG-JANSSON et al. [32] presented lower numbers of CD8+ T-cell activation markers (CD57+ and CD28+) in BAL fluid of smokers compared with nonsmokers. In comparison to previous studies in the airways, the present authors demonstrated that cigarette smoking increased the expression of the surface activation marker CD28 on CD8+ T-lymphocytes in peripheral blood of smokers with and without airway obstruction compared with nonsmokers (fig. 3). Where the systemic activation levels reflect a general capability to mount a higher protective T-cell response to airway infections, although these COPD-patients might be coping better with repeated infections, accumulation of activated CD8+ T-cells in peripheral blood may be followed by a lower number of CD28+ CD8+ T-cells in the airways [30]. This could be of importance for disease progression. Indeed, recurring exacerbations induced by airway infections have been implicated in declining lung function in COPD patients [33].

The present authors also investigated the systemic immunotoxicity of cigarette smoking as measured by the cytotoxic effector (CD27-/CD45RA+) peripheral blood CD8+ T-lymphocytes. It was found that cigarette smoking increased the percentage of cytotoxic effector CD8+ T-lymphocytes in peripheral blood of smokers and COPD patients compared with nonsmokers (fig. 5). This subpopulation of CD8+ 
T-lymphocytes causes lysis of target cells via two mechanisms: 1) membranolysis, in which secreted molecules, such as perforin and granzymes, form pores in the membrane of target cells [17]; and 2) apoptosis, mediated by the triggering of apoptosis-inducing (Fas-like) surface molecules of the target cells [17, 34, 35]. Moreover, cigarette smoke reduced chemotactic activity of peripheral blood CD8+ T-cells to MCP-1 at a concentration of $0.125 \mu \mathrm{g} \cdot \mathrm{mL}^{-1}$ (fig. 4), but did not change the spontaneous migration of CD8+ T-lymphocytes of smokers with and without COPD compared with nonsmokers. Interestingly, these smoking-induced significant changes in chemotactic activity to $\mathrm{MCP}-1$ could not be found at a higher concentration of $0.25 \mu \mathrm{g} \cdot \mathrm{mL}^{-1}$. This indicates that the response of T-cells to MCP-1 is dose-dependent [13]. The observation that cigarette smoke reduced the chemotactic activity but induced a higher cytotoxicity and activation of peripheral blood CD8+ T-lymphocytes underscores the thesis that cigarette smoke induces the extravasation predominantly of memory, rather than cytotoxic CD8+ T-cells, in order to prolong cytotoxic effector CD8+ T-cell effects in local compartments [13].

In conclusion, the present findings demonstrate that surface antigen modification on peripheral blood CD8+ T-lymphocytes plays an important role in the pathogenesis of chronic obstructive pulmonary disease and that this may be generated only in part by cigarette smoking. The scientific significance and validity of the present results may be influenced by small sample sizes, age, smoking history and sex in each group. These effects could potentially affect the clinical relevance of the present findings and should, therefore, be addressed in future studies.

\section{REFERENCES}

1 Saetta M, Mariani M, Panina-Bordignon $\mathrm{P}$, et al. Increased expression of the chemokine receptor $\mathrm{CXCR}_{3}$ and its ligand CXCL10 in peripheral airways of smokers with chronic obstructive pulmonary disease. Am J Respir Crit Care Med 2002; 165: 1404-1409.

2 Johnson JD, Hauchens DP, Kluwe WM, Craig DK, Fisher GL. Effects of mainstream and environmental tobacco smoke on the immune system in animals and humans: a review. Crit Rev Toxicol 1990; 20: 369-395.

3 Sopori ML, Kozak W. Immunomodulatory effects of cigarette smoke. J Neuroimmunol 1998; 83: 148-156.

4 Holt PG, Keast D. Environmentally induced changes in immunological function: acute and chronic effects of inhalation of tobacco smoke and other atmospheric contaminants in man and experimental animals. Bacteriol Rev 1977; 41: 205-216.

5 Kalra R, Singh SP, Savage SM, Finch GL, Sopori ML. Effects of cigarette smoke on immune response: chronic exposure to cigarette smoke impairs antigen-mediated signaling in $\mathrm{T}$ cells and depletes $\mathrm{IP}_{3}$-sensitive $\mathrm{Ca}^{2+}$ stores. $\mathrm{J}$ Pharmacol Exp Ther 2000; 293: 166-171.

6 Kim WD, Kim WS, Koh Y, et al. Abnormal peripheral blood T-lymphocyte subsets in a subgroup of patients with COPD. Chest 2002; 122: 437-444.

7 Glader P, von Wachenfeldt K, Löfdahl CG. Systemic CD4+ T-cell activation is correlated with FEV1 in smokers. Respir Med 2006; 100: 1088-1093.
8 Majori M, Corradi M, Caminati A, Cacciani G, Bertaccco S, Pesci A. Predominant Th1 cytokine pattern in peripheral blood from subjects with chronic obstructive pulmonary disease. J Allergy Clin Immunol 1999; 103: 458-462.

9 Xie JH, Nomura N, Lu M, et al. Antibody-mediated blockade of the $\mathrm{CXCR}_{3}$ chemokine receptor results in diminished recruitment of $\mathrm{T}$ helper 1 cells into sites of inflammation. J Leukoc Biol 2003; 73: 771-780.

10 Leckie MJ, Jenkins GR, Khan J, et al. Sputum T lymphocytes in asthma, COPD and healthy subjects have the phenotype of activated intraepithelial $\mathrm{T}$ cells (CD69+ CD103+). Thorax 2003; 58: 23-29.

11 Lenschow DJ, Walunas TL, Bluestone JA. CD28/B7 system of T cell costimulation. Annu Rev Immunol 1996; 14: 233-258.

12 Eckberg-Jansson A, Arva E, Nilsson O, Löfdahl CG, Andersson B. A comparison of the expression of lymphocyte activation markers in blood, bronchial biopsies and bronchoalveolar lavage: evidence for an enrichment of activated $\mathrm{T}$ lymphocytes in the bronchoalveolar space. Respir Med 1999; 93: 563-570.

13 Carr MW, Roth SJ, Luther E, Rosse SS, Springer TA. Monocyte chemoattractant protein 1 acts as a T-lymphocyte chemoattractant. Proc Natl Acad Sci USA 1994; 91: 3652-3656.

14 Hamann D, Baars PA, Rep MH, et al. Phenotypic and functional separation of memory and effector human CD8+ T cells. J Exp Med 1997; 186: 1407-1418.

15 O'Shaughnessy TC, Ansari TW, Barnes NC, Jeffery PK. Inflammation in bronchial biopsies of subjects with chronic bronchitis: inverse relationship of CD8+ T lymphocytes with FEV1. Am J Respir Crit Care Med 1997; 155: 852-857.

16 Saetta M, Baraldo S, Corbino L, et al. CD8+ve cells in the lungs of smokers with chronic obstructive pulmonary disease. Am J Respir Crit Care Med 1999; 160: 711-717.

17 Chrysofakis G, Tzanakis N, Kyriakoy D, et al. Perforin expression and cytotoxic activity of sputum CD8+ lymphocytes in patients with COPD. Chest 2004; 125: 71-76.

18 Fabbri L, Pauwels RA, Hurd SS, Gold Scientific Committee. Global strategy for the diagnosis, management, and prevention of chronic obstructive pulmonary disease: GOLD Executive Summary updated 2003. COPD 2004; 1: 105-141.

19 Pauwels RA, Buist AS, Calverley PM, Jenkins CR, Hurd SS, GOLD Scientific Committee. Global strategy for the diagnosis, management, and prevention of chronic obstructive pulmonary disease. NHLBI/WHO Global Initiative for Chronic Obstructive Lung Disease (GOLD) Workshop summary. Am J Respir Crit Care Med 2001; 163: 1256-1276.

20 American Thoracic Society. Standardization of Spirometry, 1994 Update. Am J Respir Crit Care Med 1995; 152: 1107-1136.

21 Goldman HI, Becklake MR. Respiratory function tests; normal values at median altitudes and the prediction of normal results. Am Rev Tuberc 1959; 79: 457-467.

22 Jinquan T, Larsen CG, Gesser B, Matsushima K, ThestrupPedersen K. Human IL-10 is a chemoattractant for CD8+ $\mathrm{T}$ lymphocytes and an inhibitor of IL-8-induced CD4+ T-lymphocyte migration. J Immunol 1993; 151: 4545-4551.

23 Saetta M. Airway inflammation in chronic obstructive pulmonary disease. Am J Respir Crit Care Med 1999; 160: S17-S20.

24 Saetta M, Di Stefano A, Turato G, et al. CD8+ T-lymphocytes in the peripheral airways of smokers with 
chronic obstructive pulmonary disease. Am J Respir Crit Care Med 1998; 157: 822-826.

25 Tzanakis N, Chrysofakis G, Tsoumakidou M, et al. Induced sputum CD8+ T-lymphocyte subpopulations in chronic obstructive pulmonary disease. Respir Med 2004; 98: 57-65.

26 Amadori A, Zamarchi R, De Silvestro G, et al. Genetic control of the CD4/CD8 T-cell ratio in humans. Nat Med 1995; 1: 1279-1283.

27 Clementi M, Forabosco P, Amadori A, et al. CD4 and CD8 $\mathrm{T}$ lymphocyte inheritance. Evidence for major autosomal recessive genes. Hum Genet 1999; 105: 337-342.

28 Hogg JC. Role of latent viral infections in chronic obstructive pulmonary disease and asthma. Am J Respir Crit Care Med 2001; 164: S71-S75.

29 de Jong JW, van der Belt-Gritter B, Koeter GH, Postma DS. Peripheral blood lymphocyte cell subsets in subjects with chronic obstructive pulmonary disease: association with smoking, IgE and lung function. Respir Med 1997; 91: 67-76.

30 Barnes PJ, Cosio MG. Characterization of T - lymphocytes in chronic obstructive pulmonary disease. PLoS Med 2004 Oct, $11 \mathrm{e} 20$.
31 Hogg JC, Chu F, Utokaparch S, et al. The nature of smallairway obstruction in chronic obstructive pulmonary disease. New Engl J Med 2004; 350: 2645-2653.

32 Ekberg-Jansson A, Andersson B, Avra E, Nilsson O, Löfdahl CG. The expression of lymphocyte surface antigens in bronchial biopsies, bronchoalveolar lavage cells and blood cells in healthy smoking and neversmoking men, 60 years old. Respir Med 2000; 94: 264-272.

33 Donaldson GC, Seemungal TA, Bhowmik A, Wedzicha JA. Relationship between exacerbation frequency and lung function decline in chronic obstructive pulmonary disease. Thorax 2002; 57: 847-852.

34 Berke G. The binding and lysis of target cells by cytotoxic lymphocytes: molecular and cellular aspects. Annu Rev Immunol 1994; 12: 735-773.

35 Liu AN, Mohammed AZ, Rice WR, et al. Perforinindependent CD8+ T-cell-mediated cytotoxicity of alveolar epithelial cells is preferentially mediated by tumor necrosis factor-alpha: relative insensitivity to Fas ligand. Am J Respir Cell Mol Biol 1999; 20: 849-858. 